\title{
Asthma management programs in managed care organizations
}

Christine W. Hartmann MSS, PhD

Jefferson Medical College

Vittorio Maio PharmD, MS

Jefferson Medical College

Neil I. Goldfarb

Jefferson Medical College

Nicole M. Cobb MAOM

Jefferson Medical College

David B. Nash

Jefferson Medical College

Follow this and additional works at: https://jdc.jefferson.edu/healthpolicyfaculty

Part of the Health Services Research Commons

Let us know how access to this document benefits you

\section{Recommended Citation}

Hartmann, Christine W. MSS, PhD; Maio, Vittorio PharmD, MS; Goldfarb, Neil I.; Cobb, Nicole M. MAOM; and Nash, David B., "Asthma management programs in managed care organizations" (2005). College of Population Health Faculty Papers. Paper 27.

https://jdc.jefferson.edu/healthpolicyfaculty/27

This Article is brought to you for free and open access by the Jefferson Digital Commons. The Jefferson Digital Commons is a service of Thomas Jefferson University's Center for Teaching and Learning (CTL). The Commons is a showcase for Jefferson books and journals, peer-reviewed scholarly publications, unique historical collections from the University archives, and teaching tools. The Jefferson Digital Commons allows researchers and interested readers anywhere in the world to learn about and keep up to date with Jefferson scholarship. This article has been accepted for inclusion in College of Population Health Faculty Papers by an authorized administrator of the Jefferson Digital Commons. For more information, please contact: JeffersonDigitalCommons@jefferson.edu. 


\title{
Asthma Management Programs in Managed Care Organizations
}

\author{
CHRISTINE W. HARTMANN, M.S.S., Ph.D., VITTORIO MAIO, Pharm.D., M.S., \\ NEIL I. GOLDFARB, NICOLE COBB, M.A.O.M., and DAVID B. NASH, M.D., M.B.A.
}

\begin{abstract}
The aim of this work was to investigate how managed care organizations (MCOs) currently approach asthma treatment and management and to determine factors affecting asthma outcomes. A Web-based survey was administered to a national sample of 351 medical directors of MCOs to investigate the asthma management program components in their organizations as well as gaps and barriers in the management of patients with asthma. All $134(38.2 \%)$ responding medical directors reported that their organizations monitor asthma patients. Plans use a variety of asthma management activities, including general member education (90\%), member education by mail (87\%), self-management education $(85 \%)$, and provider education $(82 \%)$. Educational resources $(89 \%)$ and telephone advice nurse $(77 \%)$ were the most common self-management strategies offered. Among factors impeding the provision of effective asthma care, noncompliance with asthma treatment, the inappropriate use of medications, and the need for multiple medications were cited by virtually all respondents. Health plans rely on an array of strategies to manage asthma patients. Education encouraging patient self-management is a key component of asthma management programs. However, a considerable number of treatment approach barriers are impeding the achievement of proper asthma care. Without innovative approaches to care, it appears that current MCOs' asthma management efforts may not result in substantial improvements in asthma outcomes. (Disease Management 2005;8:339-345)
\end{abstract}

\section{INTRODUCTION}

$\mathbf{W}$ ITH ITS GENERAL INCREASE in prevalence, morbidity, and mortality over the last decades, asthma is one of the most prominent and costly public health challenges in children and adults. ${ }^{1-3}$ Currently, asthma affects approximately 15 million individuals in the United States. On an annual basis, 5,000 deaths, 500,000 hospitalizations, and 2 million emergency department visits are attributed to asthma. ${ }^{4-6}$ In addition, asthma accounts for 14 million school absence days and 14.5 million work absence days annually. ${ }^{4}$ Accordingly, the economic impact for society is astonishing: direct and indirect health care costs for asthma were estimated to be $\$ 12.7$ billion in 1998 . $^{1,6,7}$

According to the National Heart, Lung, and Blood Institute's (NHLBI) current guidelines, asthma treatment entails a multilevel intervention including appropriate pharmacological therapy, patient education, control of asthma

Department of Health Policy, Jefferson Medical College, Philadelphia, Pennsylvania. 
triggers, and monitoring of asthma severity with objective measures of lung function. ${ }^{1}$ The literature reports, however, that compliance with guidelines falls short. ${ }^{8-10}$ Suboptimal use of effective medications, gaps in communication between patients and physicians, and inadequate patient disease self-management are among the most important reasons for this failure. ${ }^{11}$

With the objectives of optimizing the process of care provided to patients and enhancing healthcare outcomes, disease management (DM) programs for asthma have become a priority for managed care organizations (MCOs). For almost a decade, encouraged by a number of successful programs showing improvements in terms of both clinical and humanistic outcomes, ${ }^{12-17}$ asthma DM programs have been flourishing across the country. One survey of members of America's Health Insurance Plans (formerly the American Association of Health Plans) reported that over three quarters of plans surveyed had an asthma DM program in place in $2000 .{ }^{18}$ However, there is limited information on how such programs are structured. The purpose of this survey was to determine how MCOs currently approach asthma treatment and management, and to identify their biggest challenges and opportunities in improving asthma outcomes.

\section{METHODS}

A Web-based survey was conducted in April and May of 2004. The target population of the survey consisted of all medical directors of MCOs in the United States. The sample list was obtained from InterStudy Publication's Competitive Edge Part I \& II (version 13.2), which provided 455 medical directors' names and addresses, listed as of January 1, 2003 (the most recent available listing at the time the study was initiated). Duplicate names were removed. The list was subsequently cross-tabulated with the Department of Health Policy's database of managed care medical directors to determine email addresses and direct telephone numbers. Efforts were made to obtain accurate e-mail addresses and phone numbers of all medical directors listed.

The final sample consisted of 351 medical directors. A letter of invitation was e-mailed to all potential respondents in the cleaned list, ex- plaining the survey and asking for their participation in the survey. A link to the online survey instrument was provided in the letter. Potential participants were assured of the confidentiality of the information collected. A financial incentive of $\$ 50$ upon completion of the questionnaire also was offered.

\section{Data collection}

A survey questionnaire was developed by the project team and mounted on the online survey portal www.SurveyMonkey.com. The instrument contained questions regarding descriptive plan information, asthma management program components, and gaps and barriers in the management of patients with asthma. All survey instruments and procedures were reviewed and approved by the Thomas Jefferson University Institutional Review Board.

Responses were tracked through the survey portal. Three follow-up emailings were sent in 1-week intervals to non-respondents, and those who requested a printed copy of the survey were sent one. Two weeks after the final follow-up mailing, phone calls were placed to a random sample of 20 non-respondents to determine whether making direct phone calls would further elevate response rates. This attempt was unsuccessful:

\begin{tabular}{|c|c|c|c|}
\hline \multirow{2}{*}{$\begin{array}{l}\text { Enrollment size } \\
\text { by book of business }{ }^{c}\end{array}$} & \multicolumn{3}{|c|}{$\mathrm{n}(\%)^{\mathrm{a}, \mathrm{b}}$} \\
\hline & Commercial & Medicaid & Medicare \\
\hline None & $23(17)$ & $52(40)$ & $75(57)$ \\
\hline $1-50,000$ & $28(21)$ & $41(31)$ & $39(30)$ \\
\hline $50,001-100,000$ & $21(16)$ & $19(14)$ & $8(6)$ \\
\hline $100,001-500,000$ & $35(27)$ & $16(12)$ & $6(5)$ \\
\hline$>500,000$ & 25 (19) & $4(3)$ & $4(3)$ \\
\hline \multicolumn{4}{|l|}{ Region } \\
\hline National ${ }^{\mathrm{d}}$ & & $18(14)$ & \\
\hline Midwest & & $38(29)$ & \\
\hline Northeast & & 25 (19) & \\
\hline South & & $30(23)$ & \\
\hline West & & 22 (17) & \\
\hline \multicolumn{4}{|c|}{$\begin{array}{l}\text { aTotals may not sum } 100 \% \text { due to rounding. } \\
\text { bNot available for all respondents. } \\
{ }^{\mathrm{c} M u l t i p l e-r e s p o n s e} \text { question. } \\
{ }^{\mathrm{d} C h a r a c t e r i z e d ~ a s ~ t h o s e ~ M C O s ~ r e p o r t i n g ~ m e m b e r-~} \\
\text { ship in at least two regions. }\end{array}$} \\
\hline
\end{tabular}


Table 2. Methods of Identifying Patients With Asthma $(n=134)$

\begin{tabular}{lc}
\hline Measurement & $\mathrm{n}(\%)^{\mathrm{a}, \mathrm{b}}$ \\
\hline $\begin{array}{l}\text { Claims or encounter date (e.g., CPT-4, } \\
\quad \text { ICD-9 codes) }\end{array}$ & $129(97)$ \\
Pharmacy utilization data (e.g., NDC & $129(97)$ \\
$\quad$ codes) & $100(75)$ \\
Care manager referral & $91(68)$ \\
Physician referral & $77(58)$ \\
Self-referral & $73(55)$ \\
HEDIS & $41(31)$ \\
Predictive modeling software & $41(31)$ \\
Member interview or self-assessment & $5(4)$ \\
Other & $2(2)$ \\
We do not identify patients with asthma & \\
\hline \multicolumn{2}{l}{ aMultiple-response question. } \\
$\quad$ bAvailable for 133 respondents.
\end{tabular}

only one director out of the 20 completed the survey online. The survey was officially closed 2 weeks after the final follow-up mailing.

All responses were entered into the form on the survey Web site, either by the respondents themselves or, for respondents who completed the printed instrument, by a survey staff member. The complete data file was subsequently downloaded in the form of an Excel spreadsheet (Microsoft Corp, Redmond, WA).

\section{Statistical analysis}

Data were analyzed using SAS (SAS Institute, version 8.2, Cary, NC). Descriptive statistics were calculated for all variables.

\section{RESULTS}

In all, 134 medical directors completed the online survey, either online $(n=132)$ or in writing $(n=2)$, and 34 declined to participate. The final response rate was $38.2 \%$, based on 134 responses out of a sample of 351. The completion rate was $42.3 \%$, based on 134 responses out of the sample of 317 directors who did not decline.

Respondents were asked to identify basic demographic characteristics of their organizations (Table 1). Most of the plans (83\%) had some commercial members, $60 \%$ had some Medicaid members, and $43 \%$ had some Medicare members. Responses were well-distributed around the country, with a slight majority coming from either the Midwest (29\%) or the South (23\%).

Methods used by the responding MCOs to identify patients with asthma are described in Table 2. Information collected through this multiple-response question indicates that almost all responding organizations used claims or encounter data such as CPT-4 or ICD-9 codes $(97 \%)$ and pharmacy utilization data such as NDC codes (97\%) to identify patients. More than half of these organizations also used care manager referrals $(75 \%)$, physician referrals (68\%), self-referral (58\%), or the Health Plan Employer Data and Information Set (HEDIS) measures (55\%). Only two organizations did not identify asthma patients at all.

With regard to asthma management activities conducted by responding organizations, there was a large gap between activities pursued by most organizations and those pursued only by some (Table 3 ). The most popular activities were general member education (90\%), member education by mail $(87 \%)$, self-management education (85\%), and provider education (82\%). Internet member education was pursued by roughly half of the organizations, while member incentives to encourage compliance and pharmacy benefit were pursued by only $11 \%$ and $10 \%$, respectively.

\begin{tabular}{|lr|}
\hline TABle 3. Asthma Management Activities $(n=134)$ \\
\hline Component & $\mathrm{n}(\%) \mathrm{a}, \mathrm{b}$ \\
\hline General member education & $118(90)$ \\
Member education by mail & $114(87)$ \\
Self-management education & $111(85)$ \\
Provider education & $108(82)$ \\
Internet member education & $64(49)$ \\
Information Technology member support & $31(24)$ \\
Member incentives to encourage compliance & $15(11)$ \\
Pharmacy benefit, e.g., waiver of copays & $13(10)$ \\
Other management strategy & $19(15)$ \\
\hline \multicolumn{2}{l}{${ }^{a}$ Multiple-response question. } \\
\multicolumn{2}{l}{ bAvailable for 131 respondents. } \\
\hline
\end{tabular}


Table 4. Member Self-Management Strategies OFFERED $(n=134)$

\begin{tabular}{lc}
\hline Component & $\mathrm{n}(\%)^{\mathrm{a}, \mathrm{b}}$ \\
\hline Educational resources & $119(89)$ \\
Telephone advice nurse & $102(77)$ \\
Self-assessment of peak flow & $79(59)$ \\
Behavior modification programs & $77(58)$ \\
$\begin{array}{l}\text { Home visits (assessment of environmental } \\
\text { triggers) }\end{array}$ & $46(35)$ \\
$\begin{array}{l}\text { Member/dependent skills training } \\
\text { Other self-management strategies }\end{array}$ & $46(35)$ \\
No self-management strategies & $6(5)$ \\
\hline aMultiple-response question. & $6(5)$ \\
\hline bAvailable for 133 respondents. & \\
\hline
\end{tabular}

As evidenced by the data in Table 3, asthma self-management strategies comprised part of most organizations' asthma management activities. The specific types of self-management strategies offered are detailed in Table 4. Only $5 \%$ of the organizations reported using no selfmanagement strategies. Educational resources were most frequently employed (89\%), with telephone advice nurse services also being used by over three quarters of responding organizations. Almost $60 \%$ of the organizations also made use of self-assessment of peak flow and behavior modification programs.

Organizations also were asked about the ways in which they assessed the effectiveness of the management of members with asthma (Table 5). There was a large variation in the types of measures used. Most plans were examining emergency room (95\%) and inpatient hospital $(91 \%)$ service utilization. Other frequently used measures included pharmacy cost utilization (80\%) and quality measures such as HEDIS and Foundation for Accountability (FACCT; 78\%). Organizations also were interested in oral steroid use (60\%). All other methods, including member satisfaction, return on investment, clinical outcome measures, and days missed from work or school were used by fewer than half the organizations.

Respondents were asked to rate on a threeitem scale (not at all, somewhat, and extensively) the extent to which certain factors im- peded the provision of effective asthma care from the perspective of the MCO (Table 6). Based on a total percentage combination of the somewhat and extensively categories, noncompliance with asthma treatment and inappropriate use of medications were cited as impeding factors by $99 \%$ (all but one respondent) and $97 \%$ (all but four respondents), respectively. Other frequently cited impeding factors include the need for taking multiple medications $(96 \%)$, the variability of the disease within an individual $(95 \%)$, patient psychosocial issues $(94 \%)$, and lack of provider awareness of the NHLBI guidelines for asthma (83\%).

In a related question, respondents were asked to rate, using a three-item scale (does not, somewhat, and significantly), the factors that affect member compliance with the prescribed treatment regimen (Table 7). Patient misunderstanding of the role of prescribed medications in managing asthma was rated as significantly affecting compliance by $79 \%$ of the respondents, while lack of basic knowledge about asthma as a disease and lack of understanding of specific personal asthma triggers were cited as significant

\begin{tabular}{|lc|}
\hline \multicolumn{2}{|c|}{ TABle 5. METHODS OF AsSESING THE EFFECTIVENESS } \\
OF MANAGING MEMBERS WITH AstHMA $(n=134)$ \\
\hline Measurement & $\mathrm{n}(\%)^{\mathrm{a}, \mathrm{b}}$ \\
\hline Emergency room utilization & $124(95)$ \\
Inpatient utilization & $118(91)$ \\
Pharmacy costs/utilization & $104(80)$ \\
Quality measures (eg, HEDIS, FACCT) & $101(78)$ \\
Oral steroid use & $78(60)$ \\
Member satisfaction & $55(42)$ \\
Specialist utilization & $41(32)$ \\
Return on investment & $38(29)$ \\
Clinical outcome measures (eg, peak flow) & $34(26)$ \\
Functional status assessment & $33(25)$ \\
Lost work days & $22(17)$ \\
Lost school days & $21(16)$ \\
Provider satisfaction & $19(15)$ \\
Employer satisfaction & $8(6)$ \\
Member longevity program & $8(6)$ \\
Other & $3(2)$ \\
\hline aMultiple-response question. & \\
bAvailable for 130 respondents. & \\
\hline
\end{tabular}




\begin{tabular}{|c|c|c|c|}
\hline \multirow[b]{2}{*}{ Factor } & \multicolumn{3}{|c|}{$\mathrm{n}(\%)^{\mathrm{a}, \mathrm{b}}$} \\
\hline & Not at all & Somewhat & Extensively \\
\hline Member noncompliance with asthma treatment ${ }^{\mathrm{C}}$ & $1(1)$ & $63(48)$ & $68(52)$ \\
\hline Member inappropriate use of medications ${ }^{\mathrm{d}}$ & $4(3)$ & $80(60)$ & $49(37)$ \\
\hline Variability of the disease within an individual ${ }^{d}$ & $7(5)$ & $86(65)$ & $40(30)$ \\
\hline Member need to take multiple medications ${ }^{c}$ & $5(4)$ & $88(67)$ & $39(30)$ \\
\hline Member psychosocial issues ${ }^{\mathrm{e}}$ & $8(6)$ & $86(67)$ & $35(27)$ \\
\hline $\begin{array}{l}\text { Lack of provider awareness of the NHLBI Guidelines for } \\
\text { Asthma }\end{array}$ & $22(17)$ & $86(65)$ & $25(19)$ \\
\hline Resource limitations (financial and non-financial) ${ }^{\mathrm{d}}$ & $24(18)$ & $85(64)$ & $24(18)$ \\
\hline Member literacy level ${ }^{\mathrm{d}}$ & $18(14)$ & $96(72)$ & $19(14)$ \\
\hline Inability of providers to follow up with patients ${ }^{c}$ & $32(24)$ & $81(61)$ & $19(14)$ \\
\hline Cost of the program for member, for asthma-related services ${ }^{\mathrm{d}}$ & $60(45)$ & $56(42)$ & $17(13)$ \\
\hline Individual member response to asthma medications ${ }^{\mathrm{d}}$ & $14(11)$ & $103(77)$ & $16(12)$ \\
\hline Multicultural issues ${ }^{\mathrm{C}}$ & $19(14)$ & $103(78)$ & $10(8)$ \\
\hline Information technology limitations ${ }^{\mathrm{d}}$ & $54(41)$ & $72(54)$ & $7(5)$ \\
\hline Plan inability to identify members with asthma ${ }^{c}$ & $87(66)$ & $40(30)$ & $5(4)$ \\
\hline 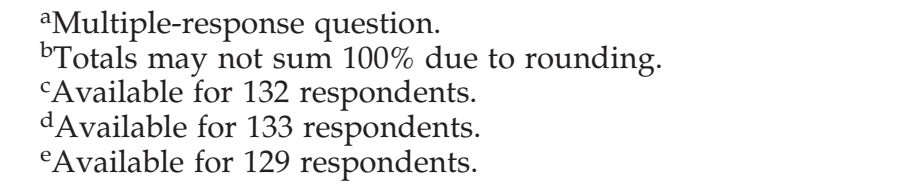 & & & \\
\hline
\end{tabular}

factors by $73 \%$ and $68 \%$, respectively. Overall, medication safety or concerns about side effects ranked lowest, with $19 \%$ of respondents indicating that it was not an issue, and $71 \%$ indicating it was somewhat an issue.
Respondents were asked to outline their beliefs regarding members' use of asthma medications (Table 8). To this single-response question, only $5 \%$ of respondents indicated that they believed members used medications as

\begin{tabular}{|c|c|c|c|}
\hline \multirow[b]{2}{*}{ Factor } & \multicolumn{3}{|c|}{$\mathrm{n}(\%)^{\mathrm{a}}$} \\
\hline & Does not & Somewhat & Significantly \\
\hline $\begin{array}{l}\text { Misunderstanding the role of prescribed medications in } \\
\text { managing his/her asthmab,d }\end{array}$ & 0 & $28(21)$ & $103(79)$ \\
\hline Lack of basic knowledge of asthma as a disease $\mathrm{e}^{\mathrm{c}, \mathrm{d}}$ & $2(2)$ & $34(26)$ & $96(73)$ \\
\hline Lack of understanding of his/her specific asthma triggers ${ }^{b, d}$ & $1(1)$ & $41(31)$ & $89(68)$ \\
\hline Need to use multiple medications ${ }^{\mathrm{b}, \mathrm{d}}$ & 0 & $69(53)$ & $62(47)$ \\
\hline Cost/financial concerns ${ }^{c}$ & $8(6)$ & $68(51)$ & $57(43)$ \\
\hline Medication safety/side effect concerns ${ }^{\mathrm{c}, \mathrm{e}}$ & $24(19)$ & $91(71)$ & $14(11)$ \\
\hline \multicolumn{4}{|c|}{$\begin{array}{l}\text { aTotals may not sum } 100 \% \text { due to rounding. } \\
\text { bAvailable for } 132 \text { respondents. } \\
\text { cAvailable for } 133 \text { respondents. } \\
\text { dOne respondent marked "not sure" category (not included in table analyses). } \\
\text { eFour respondents marked "not sure" category (not included in table analyses). }\end{array}$} \\
\hline
\end{tabular}


Table 8. Asthma Medications Used by $\operatorname{MembeRs}(n=134)^{\mathrm{a}}$

\begin{tabular}{lc}
\hline & $\mathrm{n}(\%)$ \\
\hline $\begin{array}{l}\text { Overutilization of "rescue" medications } \\
\text { and underutilization of "control" }\end{array}$ & $86(65)$ \\
medications & \\
Underutilization of "control" medications & $26(20)$ \\
Overutilization of "rescue" medications & $7(5)$ \\
Use of medications as prescribed & $7(5)$ \\
Do not know & $4(3)$ \\
Other & $3(2)$ \\
\hline \multicolumn{2}{c}{ aAvailable for 133 respondents. }
\end{tabular}

prescribed. The majority of respondents (65\%) believed that members overutilized "rescue" medications and underutilized "control" medications. Regarding underutilization alone, $20 \%$ believed this to be the case, and 5\% believed that members overutilized "rescue" medications.

\section{DISCUSSION}

This national survey of managed care medical directors provides evidence that asthma is widely recognized as an important target for disease (and cost) management efforts. Responding managed care medical directors recognized that education encouraging patient self-management is needed in order to overcome barriers to achieving asthma care goals due to member noncompliance and inappropriate use of medications. They indicated that these barriers are compounded by the complexity of pharmacotherapy, reliance on multiple medications, and attempts to address variability of disease across individual patients. The majority of respondents believed that patients are not receiving medication therapy consistent with NHLBI guidelines but instead are over-reliant on rescue therapies and underadherent to control medication. Paradoxically, despite these recognized challenges, most responding plans had traditional patient and provider education programs in place, and fewer plans were engaged in more innovative strategies, such as those employing technology or financial incentives, to influence behavior.
Based on the data collected, the evaluation of the effectiveness of asthma management strategies also relied more heavily on traditional measures of service utilization and cost, rather than on clinical and humanistic outcomes. Only 26\% of respondents were measuring clinical outcomes such as peak flows, and 17\% of plans reported measuring lost productivity. The survey results provide some confirmation that, while plans are concerned with providing high quality, the metrics used to evaluate programs still are largely focused on costs.

Subgroup analyses did not reveal any major differences in barriers to management or management approaches across regions, or by panel size or type (commercial, Medicaid, or Medicare), demonstrating that the managed care community faces common challenges to management of asthma. Therefore, plans which are experimenting with new and innovative approaches to management are encouraged to evaluate their efforts using a variety of relevant metrics and to share these findings with the broader managed care community.

The largest limitation to interpreting results from a survey research project often is the potential for response bias (ie, respondents differed systematically from nonrespondents). In this survey of the most senior medical directors in a $100 \%$ sample of health plans, a $38 \%$ response rate was achieved. It is possible that nonresponders were more likely to be those plans which are not actively involved in asthma management, and although the descriptive statistics in Table 1 suggest that the sample was representative with regard to demographic characteristics, results should be generalized with caution. An additional potential for bias arises from the survey being targeted to medical directors, who may tend to explain gaps in care in a similar fashion across many disease states. Furthermore, the survey consisted of close-ended items and may not have adequately captured the depth or variation in participants' experiences.

\section{CONCLUSION}

This national survey of managed care medical directors supports the position that asthma 
management is receiving attention from nearly all managed care plans. Education, particularly regarding self-management, appears to be an essential part of most plans' approaches to disease and cost management. However, given the inherent complexity in administering current pharmacotherapies, these existing educational efforts alone may not be enough to improve outcomes significantly. In the future, the availability of simplified therapeutic options may help, and overall, more innovative, multidimensional approaches should be developed and evaluated using a variety of metrics.

\section{ACKNOWLEDGMENTS}

We would like to thank Vox Medica for the contribution and input into survey tool design and results interpretation. This research was supported by a grant from AstraZeneca.

\section{REFERENCES}

1. National Asthma Education and Prevention Program. Expert Panel Report II: Guidelines for the Diagnosis and Management of Asthma (publ. no. 97-405). Bethesda, MD: National Institutes of Health, 1997.

2. Global Initiative for Asthma. Global Strategy for Asthma management and Prevention (publ. no. 023659). Bethesda, MD: National Institutes of Health, 2002 Available: 〈http://www.ginasthma.com〉, accessed March 14, 2004.

3. Akinbami LJ, Schoendorf KC. Trends in childhood asthma: prevalence, health care utilization, and mortality. Pediatrics 2002;110:315-322.

4. Mannino DM, Homa DM, Akinbami LJ, et al. Surveillance for asthma-United States, 1980-1999. MMWR 2002;51:1-13.

5. American Lung Association. Trends in asthma morbidity and mortality [On-line]. Available: 〈http:// www.lungusa.org/data/asthma / ASTHMAdt.pdf $\rangle$, accessed March 14, 2004.

6. Hall MJ, Owings MF. 2000 National Hospital Discharge Survey. Advance Data from Vital and Health Statistics, No. 329. Hyattsville, MD: National Center for Health Statistics, 2002.

7. Weiss KB, Sullivan SD. The health economics of asthma and rhinitis. I. Assessing the economic impact. J Allergy Clin Immunol 2001;107:3-8.
8. Legorreta AP, Christian-Herman J, O'Connor RD, Hasan MM, Evans R, Leung KM. Compliance with national asthma management guidelines and specialty care: a health maintenance organization experience. Arch Intern Med 1998;158:457-464.

9. Adams RJ, Fuhlbrigge A, Guilbert T, Lozano P, Martinez F. Inadequate use of asthma medication in the United States: results of the asthma in America national population survey. J Allergy Clin Immunol 2002;110:58-64.

10. Halterman JS, Aligne CA, Auinger P, McBride JT, Szilagyi PG. Inadequate therapy for asthma among children in the United States. Pediatrics 2000;105:272-276.

11. Stoloff S. Current asthma management: the performance gap and economic consequences. Am J Manag Care 2000;6:S918-S925.

12. Beckham S, Kaahaaina D, Voloch KA, Washburn A. A community-based asthma management program: effects on resource utilization and quality of life. Hawaii Med J 2004;63:121-126.

13. Patel PH, Welsh C, Foggs MB. Improved asthma outcomes using a coordinated care approach in a large medical group. Dis Manag 2004;7:102-111.

14. Kallenbach A, Ludwig-Beymer P, Welsh C, Norris J, Giloth B. Process improvement for asthma. An integrated approach. I Nurs Care Qual 2003;18:245-256.

15. Buchner DA, Butt LT, De Stefano A, Edgren B, Suarez A, Evans RM. Effects of an asthma management program on the asthmatic member: patient-centered results of a 2-year study in a managed care organization. Am J Manag Care 1998;4:1288-1297.

16. Lucas DO, Zimmer LO, Paul JE, et al. Two-year results from the asthma self-management program: long-term impact on health care services, costs, functional status, and productivity. I Asthma 2001;38: 321-330.

17. Lukacs SL, France EK, Baron AE, Crane LA. Effectiveness of an asthma management program for pediatric members of a large health maintenance organization. Arch Pediatr Adolesc Med 2002;156:872-876.

18. Welch WP, Bergsten C, Cutler C, Bocchino C, Smith RI. Disease management practices of health plans. Am J Manag Care 2002;8:353-361.

Address reprint requests to: Christine W. Hartmann, M.S.S., Ph.D. Department of Health Policy Jefferson Medical College 1015 Walnut St., Ste. 115 Philadelphia, PA 19107

E-mail: christine.hartmann@jefferson.edu 